\title{
Corpo(s) em movimentos: trajetória(s) corpórea(s) de mulheres brasileiras migrantes
}

Trilhando o caminho

A estrutura da apresentação deste dossiê foge um pouco à regra e começa com uma sessão de agradecimentos.

Um agradecimento ao comitê editorial da cadernos pagu que, em meados do ano de 2020, quando a vida como conhecíamos já havia sido inteiramente desestruturada pelo invisível coronavírus, encontrou tempo para analisar nossa proposta de dossiê e aceitou este ousado desafio. Em meio a uma pandemia que forçou a suspensão de quase todas as formas de mobilidade, os artigos publicados neste número analisam a experiência migratória das mulheres brasileiras por meio de abordagens absolutamente originais e inovadoras. Não poderia ser mais oportuno pensar movimento e experiências transfronteiriças de mulheres brasileiras em um momento em que vivíamos a patologização da mobilidade tida como principal meio de propagação do vírus e quando muitas vozes anunciavam o fim 'do paradigma da mobilidade' (Cresswell, 2020; Lin; Yeoh, 2021). Os artigos aqui reunidos mostram como o(s) corpo(s) das mulheres categorizadas pela nacionalidade brasileira está(ão) sempre em movimento e ocupa(m) uma posição central em suas trajetórias migratórias.

Um agradecimento também as revisoras e revisores que contribuíram anonimamente para garantir a qualidade deste dossiê. O trabalho de revisão de artigos é um espaço fundamental de diálogo com as autoras e autores, que oferece pistas e questões valiosas para pensar os problemas propostos. A apreciação anônima de artigos é um exemplo concreto do caráter inerentemente coletivo da produção de conhecimento. Não é necessariamente a mais prazerosa das atividades académicas, entretanto, posto que quase nunca recebe o devido reconhecimento público.

No contexto de pressão extenuante da academia neoliberal por 'produtividade', a pandemia agravou a precariedade das condições de trabalho com as demandas de aulas remotas, de conteúdos para as plataformas de educação a distância, de adaptações para a conclusão de trabalhos de campos, dentre outras. O aumento do trabalho doméstico e de cuidado tornou o tempo já escasso ainda mais valioso, requerendo uma escolha cuidadosa dos compromissos a serem assumidos. A contribuição dos avaliadores em meio a esse contexto tornou-se, portanto, inestimável.

Um último agradecimento volta no tempo, mais precisamente ao ano de 2019 quando, apesar de as fronteiras não estarem igualmente abertas a todos os corpos, alguns espaços acadêmicos configuravam-se como encontros de diversidade. À Beatriz Padilla, com quem organizei o painel Brazilian emigration: what you know and what it is new about no Congresso da Associação de Estudos Latino Americanos (LASA). À Tamaki Watari e Nádia Luna Treillard, que no mesmo ano organizaram a sessão Quando migrantes femininas (re)encontram o(s) "corpo(s) brasileiro(s): os casos da Europa, do Japão e do Brasil no Congresso da Associação de Brasilianistas na Europa (ABRE). Ambos eventos foram o início de uma colaboração feminista e transnacional entre as autoras aqui reunidas, que se mantém até os dias de hoje. Em 2021, partilhamos mais uma vez um painel conjunto no Congresso da ABRE. Muitas das questões aqui apresentadas foram discutidas e amadurecidas nesses encontros, alimentando nosso interesse em organizar o presente dossie que não pretende oferecer conclusões ou respostas sobre a diversidade da experiência mulheres brasileiras migrantes e seu(s) corpo(s) brasileiro(s). Antes, tem como objetivo constituir-se como espaço de diálogo com um público maior. 
A impressão da colonialidade no(s) corpo(s) brasileiro(s) das mulheres brasileiras imigrantes

As trajetórias e vivências transfronteiriças e transnacionais de mulheres brasileiras têm sido objeto de crescentes estudos nacionais (Carpenedo; Nardi, 2017; De Oliveira Assis, 2014; Escudero, 2016; Fleischer, 2003; Piscitelli, 2008a, 2008a; Piscitelli; Assis; Olivar, 2011; Pontes, 2004) e internacionais (Gomes, 2013; Lidola, 2015; Lucchese Et Al., 2021; Mcdonnell; Lourenço, 2009; Mcilwaine; Evans, 2020; Messias, 2002; Padilla; França, 2015; Watarai, 2014). Tal multiplicidade de interesses dá-se tanto pelo seu aumento exponencial e a diversificação de destinos, bem como pela complexidade de sentidos, materialidade e significados. De maneira geral, a literatura existente tem se dedicado largamente, em nível macro, aos processos de constituição e direcionalidade dos fluxos migratórios, inserção e/ou precarização laboral, acolhimentos, cidadania, (ir)regularidades $e$ acesso à saúde, por exemplo. Em perspectivas mais contextuais, e complementares, muito do debate acadêmico tem se voltado à questões acerca de processos identitários, afetos, racialização $e$ sexualização, agências, entre outros.

A migração das mulheres brasileiras, para além de um e deslocamento geográfico, é um fenômeno social atravessado por clivagens de gênero, classe, raça. Como em outras dinâmicas societais, tais clivagens organizam de forma particular as experiências dessas mulheres, forçando negociações constantes sobre suas identidades/identificações e seu(s) corpo(s) brasileiro(s) tanto nos países de origem quanto nos de destino (Donato et al., 2006; Hondagneu-Sotelo, 2011).

Devido à posição subalterna nas matrizes de relação de poder, em suas trajetórias migratórias, as mulheres brasileiras vivenciam intensas convergências de processos de estigmatização, sexualização e racialização que moldam suas experiências e subjetivações corporais (Piscitelli, 2008b). Interseccionalidade e colonialidade, portanto, apresentam-se como conceitos-chave para pensar as experiências migratórias dessas mulheres em contextos de múltiplos sistemas de poder e hierarquias (Carneiro, 2003; Crenshaw, 1991; González, 1984; Lugones, 2008; Paredes, 2008). Como Mahler e Pessar (2001) afirmam, a imigração de mulheres implica não apenas um deslocamento geográfico, mas engloba também continuas práticas e discursos de negociação de posições em diferentes níveis das matrizes de poder que moldam a experiência de atravessamento das fronteiras.

Os debates decoloniais têm produzido desafiadoras chaves analíticas na problematização da colonialidade resultante do binómio colonialismo-modernidade materializada em assimetrias geopolíticas, econômicas e culturais de dominação e hierarquização dos sujeitos (Quijano, 1992). Lugones (2008) avança nessas discussões, revelando que a colonialidade de gênero, como um dispositivo de dominação, impôs uma visão hegemônica e eurocêntrica dos atributos que categorizam as mulheres do Sul Global como seres subalternos e inferiores. A autora argumento que a colonialidade de gênero localiza as "mulheres do Sul Global" como sendo corpos exóticos e sexualmente disponíveis, objetificando-os em função do prazer dos homens das metrópoles (Cusicanqui, 2010; Lugones, 2008).

A essas dinâmicas de sexualização estão intrincados, também, processos de racialização que, como uma herança da história colonial, forjaram diferenças e distinções, as quais ordenaram a humanidade em categorias posteriormente convertidas em hierarquias (Ahmed, 2000). Essa prática anexou uma identidade racial aos corpos dos sujeitos das colônias investida de significados prédeterminados, transformando-os em corpos racializados (Ahmed, 2015). A racialização das mulheres das colônias deu-se, portanto, como uma experiência intrinsecamente corpórea. O dispositivo saber-poder colonial uniu a identidade das mulheres ao seu corpo (Ahmed, 2015). Aos corpos das mulheres das colônias, assim, associou-se uma identidade racial sexualizada. A medida em que a colonialidade de gênero $e$ a racialização passaram a definir os corpos das mulheres das colônias, foram também sendo empreendidas dinâmicas de inferiorização e subalternização delas em relação às mulheres brancas (Lugones, 2008).

Como mulheres da ex-colônia, as brasileiras imigrantes são construídas como 'corpo colonial' (Fanon, 2007). Um corpo racializado, libidinoso e imoral que não obedece às normas dominantes. Tendem a ser vistas, portanto, como o Outro das mulheres brancas (Ahmed, 2000). Essas dinâmicas de opressão se materializam nos dias de hoje através da exotização e erotização dessas mulheres e da sua vinculação constante ao mercado do sexo, resultando em experiências de 
discriminação e marginalização (Piscitelli, 2008a). O(s) corpo(s) brasileiro(s) das mulheres brasileiras migrantes continua(m) submetido(s) a dispositivos de controle e disciplina construídos discursivamente pelo colonialismo e mantido pela colonialidade.

$\mathrm{O}(\mathrm{s})$ corpo(s) sexualizado(s) e racializado(s) das mulheres brasileiras em seus contextos migratórios constituiem-se como uma arena de conflitos, negociações e resistências. Elas jogam com e deslizam sobre os processos de essencialização de suas existências que traduzem e aprisionam suas identidades em um "corpo feminino brasileiro unitário" disponível sexual, afetiva e laboralmente (Malheiros; Padilla, 2015; Piscitelli, 2014). Ressignificam os sentidos atribuídos ao(s) seu(s) corpo(s) brasileiro(s), corporificando práticas insurgentes e insubmissas. Práticas de recusa ao lugar subalterno de 'corpo colonial' que lhes está reservado previamente. Nesse sentido, as mulheres produzem subjetivações a partir de uma resistência combativa que desafia o discurso hegemónico e forja outras possibilidades identitárias (ver Gomes, 2013). As experiências migratórias das brasileiras expõem, portanto, uma multiplicidade de perspectivas de habitar o(s) corpo(s) brasileiro(s).

Ao nos referirmos a 'corpo(s) brasileiro(s)' nas experiências transfronteiriças e transnacional das mulheres brasileiras objetivamos refletir sobre as práticas de des/re/construção e experimentação do corpo como um corpo racializado e sexualizado. Desse modo, pensamos 'o(s) corpo(s) brasileiro(s)' como técnicas, modos, práticas de resistência, de interpretação, representação e ressignificação. Nas experiências migratórias das mulheres brasileiras, 'o(s) corpo(s) brasileiro(s)' constitui-se, simultaneamente, como experiência de opressão e de agência.

\section{Os artigos deste dossiê}

Tendo em vista as inúmeras possibilidades experimentação do(s) corpo(s) brasileiro(s) nas trajetórias e vivências transfronteiriças das mulheres brasileiras, este dossiê trata de questões como racialização, sexualização, corporalidades, feminilidades, agência, resistência, identidade(s) e masculinidades em perspectivas transnacional $e$ interseccional, levando em conta diferentes contextos geográficos e sociais. A pluralidade de performances possíveis do(s) corpo(s) brasileiro(s) nas vivências migratórias das mulheres brasileiras que o(s) negocia $(\mathrm{m})$, ressignifica $(\mathrm{m})$ ou contrapõe $(\mathrm{m})$ aos discursos e práticas de dominação, controle e disciplina que impede qualquer tentativa de aprisionamento em uma categoria fixa e 'natural'. O questionamento central que guia os artigos deste dossiê se volta para os sentidos e os lugares que o(s) corpo(s) brasileiro(s) assumem nas vivências transnacionais e transfronteiriças das mulheres brasileiras. Ou seja, como essas mulheres imaginam, vivem, percebem e sentem seu(s) corpo(s) brasileiro(s) em suas trajetórias de migração. Que transformações o(s) corpo(s) brasileiro(s) experienciam? Qual potencial de agencialidade do(s) corpo(s) brasileiro(s)? Mais ainda, perguntamos como o(s) corpo(s) brasileiro(s) das mulheres brasileiras migrantes conforma $(\mathrm{m})$ ou resiste $(\mathrm{m})$ ao lugar que lhe é previamente reservado com base em construções imaginárias preexistentes. Qual posição assume o(s) corpo(s) brasileiro(s) nos movimentos transfronteiriços das mulheres brasileiras imigrantes e em suas negociações por pertencimento em diferentes geografias.

As experiências de ativismo feminista digital das mulheres brasileiras imigrantes em Portugal é o ponto de partida para as reflexões de Thais França e Stefanie Prange de Oliveira no artigo, Brazilian migrant women as killjoys: disclosing racism in 'friendly' Portugal, o qual abre este dossiê. As autoras analisam as estratégias de resistência e enfrentamento à narrativa colonial que as constroem como um corpo racializado, sexualizado e subalterno, levadas a cabo nas redes sociais por brasileiras imigrantes em Portugal. A partir dos posts publicados pelo projeto 'Brasileiras não se calam' no Instagram e das problematizações de Ahmed sobre a busca pela felicidade, as autoras, situam o projeto como um 'coletivo feminista estraga prazeres (feminist killjoy)' que desafia a falácia do mito sobre Portugal como um país tolerante à diversidade e não-racista. França e de Oliveira argumentam que, ao colocar-se como uma plataforma de denúncia aberta nas redes sociais, o projeto 'Brasileiras não se calam' se contrapõe ao lugar de silêncio e passividade reservado às mulheres brasileiras no país.

Ainda no contexto Europeu, Maria Lidola elege o cenário alemão para analisar as estratégias de subversão das hierarquias e estigmas que envolvem a experiência laboral das mulheres 
brasileiras naquele país. A partir da análise da inserção laboral das mulheres brasileiras no setor de depilação, em seu artigo Civilizando as outras: Beleza, trabalho íntimo e encontros affectivos em Brazilian Waxing Studios em Berlim, a autora analisa como o trabalho íntimo realizado nos Waxing Studios (estúdios de depilação) se constitui como muito mais do que um serviço de remoção de pelos. Lidola argumenta que as mulheres brasileiras atuam como educadoras do corpo alemão não só para uma corporalidade categorizada como mais higiênica e mais feminina, senão também para um comportamento mais humanizado com o diferente. Apesar dos limites que atravessam os relacionamentos temporários e frágeis que se dão no contexto dos Waxing Studios, Lidola argumenta que a inserção laboral das brasileiras no setor estético alemão abre espaços de agência a que essas mulheres não experienciam em outros segmentos feminizados ou etnicizados do mercado laboral.

O artigo Aprendendo a maquiar as hierarquias: corpo "ocidental" e o "oriental" nos cursos de maquiagem da comunidade brasileira no Japão, de Tamaki Watarai, leva-nos ao Japão e segue as análises sobre corpo, beleza e agência. A partir da pesquisa de campo realizada com maquiadoras brasileiras no Japão, a autora discute os processos em que o "corpo brasileiro" se apresenta como "ocidental" em comparação ao "oriental", criando uma nova hierarquia que coloca as brasileiras em um patamar superior às japonesas. Tal constatação contraria a expectativa da hierarquia econômica existente entre os dois países, bem como das assimetrias sociais, nas quais as brasileiras se classificam como classe menos favorecida por se engajar no trabalho não qualificado no Japão. Watarai analisa como as relações entre corpo, consumo, classe social, gênero e raça possibilitam inversões de hierarquias e como isso constrói os mundos cotidianos das mulheres brasileiras no Japão.

Erica Hatugai, em seu artigo Ler, no corpo da "mestiça", beleza, corporalidades e fronteiras no parentesco nikkey. as experiências de mulheres nipodescendentes no Brasil, continua a discutir a experiência das mulheres brasileiras no contexto japonês. Seu artigo, porém, parte das concepções de parentesco entre as famílias "japonesas" no Brasil, seguindo um estudo etnográfico realizado com imigrantes de origem japonesa e nipodescendentes de diferentes gerações da região CentroOeste Paulista. A autora analisa o deslocamento migratório ao longo de diferentes gerações de descendentes de imigrantes do Japão e suas concepções nativas sobre parentesco, corporalidades e o lugar das mulheres nessas famílias. Hatugai argumenta que as mulheres "mestiças" estabelecem uma 'nova' fronteira no parentesco e, portanto, são capazes de confrontar, com suas corporalidades, os estereótipos acerca das mulheres nipodescendentes miscigenadas e não miscigenadas.

Em um contexto e social geográfico distinto, os processos de transformações identitários subjetivos é o objeto do artigo de Ariany da Silva Villar, Dareila Sharim e Beatriz Padilla, Entre la agencia y el estigma: negociaciones identitarias de brasileñas/os en Santiago de Chile desde una perspectiva Biográfica-Interseccional. Analisando a experiência de mulheres brasileiras e homens brasileiros imigrantes no Chile, as autoras trazem uma grande contribuição para a literatura sobre imigração feminina brasileira no contexto Sul-Sul. Elas exploram como as identidades narrativas das mulheres $e$ homens foram negociadas e produzidas entre agência e sujeição ao imaginário sobre a 'brasilidade', onde o corpo é o espaço destas negociações. Villa, Sharim e Padilla observam, também, que algumas mulheres brasileiras no Chile escapam ao estereótipo da "mulata"1, sendo posicionadas como "brancas". Portanto, as autoras concluem que ao contrário do que acontece em outros contextos migratórios, o processo de racialização das brasileiras no Chile compreende também um distanciamento de algumas dessas mulheres dos estereótipos tradicionalmente associados às brasileiras.

Fechando o dossiê, está o artigo Entre o Brasil e a Europa: brasileiras negociando gênero e raça nas representações sobre "a mulher brasileira de Gláucia Assis e Sueli Siqueria. Este estudo multissiatuado investiga os processos de transnacionalização e percepção das marcas da racialização e exotização que as mulheres brasileiras vivenciam ao longo de suas experiências de imigração para

\footnotetext{
1 Por "mulata" refiro a construção discursiva da mulher brasileira como essencialmente mestiça, dotada de uma sexualidade exacerbada. Nas palavras de Giacommini (1994:221) "A autêntica mulata brasileira revela-se, então, a mulher sedutora por excelência - sedutora porque sensual e disponível”.
} 
Portugal, Itália e Alemanha. As autoras analisam como essas mulheres repensam seus projetos migratórios, negociam posições de gênero e, enfrentando processos de racialização, constroem outros significados para os imaginários associados à "mulher brasileira", reiteradamente vinculados à relações de conjugalidade estabelecidas com parceiros portugueses, alemães ou italianos. $\mathrm{O}$ casamento para as mulheres entrevistadas foi importante para marcar a mudança nas expectativas temporais e na decisão de permanecer nos países de imigração, ao mesmo tempo em que se constituiu como um espaço de afetos e segurança.

Os envolvimentos afetivos afrontaram preconceitos de parentes e amigos, de modo que as mulheres entrevistadas foram desafiando o estigma e preconceito buscando se afastar dos estereótipos da mulher brasileira. As estratégias de enfretamento ao preconceito e discriminação que vivenciam diariamente passam pela ressignificação dos estereótipos sustentados pela colonialidade que as situam numa posição subalterna nas relações laborais, sociais e íntimas. Embora em alguns casos os processos de racialização e sexualização reforcem as assimetrias de poder no interior dessas relações, Assis e Siqueira ilustram como as trajetórias migratórias das brasileiras permitem, também, possibilidades de reposicionamento diante do estigma a que são confrontadas na sociedade de acolhida.

O conjunto dos artigos aqui reunidos mostra que pensar as trajetórias e experiências migratórias de mulheres brasileiras é refletir, obrigatoriamente, sobre as possibilidades $e$ ambiguidades do(s) corpo(s) brasileiro(s) nessas experiências. A abordagem amplia o entendimento de que o(s) corpo(s) brasileiro(s) não conforma $(\mathrm{m})$ uma categoria analítica estática e que, portanto, não pode $(\mathrm{m})$ ser naturalizado(s) ou homogeneizado(s). A partir das discussões aqui apresentadas, convidamos as leitoras/autoras na continuidade das analises sobre a multiplicidade de lugares $e$ papéis que o(s) corpo(s) brasileiro(s) pode $(\mathrm{m})$ ocupar nas vivências transfronteiriças e transnacionais das mulheres brasileiras. Quiçá que os desdobramentos analíticos possam incorporar as formas por meio das quais a pandemia afetou experiências das mulheres que corporificam brasilidades em movimento.

Desejamos que a leitura das nossas reflexões seja prazerosa e estimulante!

Thais França*

\section{Referêencias bibliográficas}

AHMED, S. Strange Encounters: Embodied Others in Post-coloniality. [s.l.] Psychology Press, 2000.

AHMED, S. Race as sedimented history. postmedieval: a journal of medieval cultural studies, v. 6, n. 1, p. 94 97, 1 abr. 2015 [https://doi.org/10.1057/pmed.2015.5].

CARNEIRO, S. Enegrecer o Feminismo: A situação da mulher negra na América Latina a partir de uma perspectiva de gênero. In: ASHOKA EMPREENDIMENTOS SOCIAIS (ed.). Racismos contemporâneos. RJ, Takano Cidadania, 2003, pp.49-58.

CARPENEDO, M.; NARDI, H. Maternidade transnacional e produção de subjetividade: as experiências de mulheres brasileiras imigrantes vivendo em Londres. cadernos pagu (49), Campinas, SP, Núcleo de Estudos de Gênero-Pagu/Unicamp, 2017 [https://doi.org/10.1590/18094449201700490012].

ASSIS, G. Gender and migration from invisibility to agency: The routes of Brazilian women from transnational towns to the United States. Women's Studies International Forum v. 46, 1 set. 2014, pp.33-44 [https://doi.org/10.1016/j.wsif.2014.01.003].

CRENSHAW, K. Mapping the Margins: Intersectionality, Identity Politics, and Violence against Women of Color. Stanford Law Review v. 43, n. 6, jul. 1991, pp.1241 [https://doi.org/10.2307/1229039].

CRESSWELL, T. Valuing mobility in a post COVID-19 world. Mobilities v. 0, n. 0, 20 dez. 2020, pp.1-15 [https://doi.org/10.1080/17450101.2020.1863550].

\footnotetext{
* Investigadora Integrada, Instituto Universitário de Lisboa (ISCTE-IUL), Centro de Investigação e Estudos de Sociologia, Lisboa, Portugal. thais.franca@iscte-iul.pt / ORCID: 0000-0003-1279-412X
} 
CUSICANQUI, S. R. Ch'ixinakax utxiwa: una reflexión sobre prácticas y discursos descolonizadores. [s.l.] Tinta Limón, 2010.

DONATO, K. M. et al. A Glass Half Full? Gender in Migration Studies. International Migration Review, v. 40, n. 1, 2006, pp.3-26 [https://doi.org/10.1111/j.1747-7379.2006.00001.x].

ESCUDERO, C. O protagonismo de mulheres imigrantes na construção de redes sociais para o fortalecimento identitário: o caso das Brasileiras em Chicago (EUA). REMHU: Revista Interdisciplinar da Mobilidade Humana v. 24, n. 48, dez. 2016, pp.179-196 [https://doi.org/10.1590/1980-85852503880004812].

FANON, F. The Wretched of the Earth. [s.l.] Grove/Atlantic, Inc., 2007.

FLEISCHER, S. Uma faxina na identidade de emigrantes brasileiras. Cadernos de Campo v. 11, n. 11, São Paulo, 30 mar. 2003, 1991, pp.49-67 [https://doi.org/10.11606/issn.2316-9133.v11i11p49-67].

GOMES, M. O imaginário social "Mulher Brasileira" em Portugal: uma análise da construção de saberes, das relações de poder e dos modos de subjetivação. Dados v. 56, n. 4, 2013, pp.867-900 [https://doi.org/10.1590/S0011-52582013000400005].

GONZÁLEZ, L. Racismo e sexismo na cultura brasileira. Revista Ciências Sociais Hoje, Anpocs, 1984, pp.223-244 [https://edisciplinas.usp.br/pluginfile.php/4584956/mod_resource/content/1/06\%20\%20GONZALES\%2C\%20L\%C3\%A9lia\%20-

\%20Racismo_e_Sexismo_na_Cultura_Brasileira\%20\%281\%29.pdf - acesso: 20 maio 2017].

HONDAGNEU-SOTELO, P. Gender and Migration Scholarship: An Overview from a 21st Century Perspective. Migraciones Internacionales v. 6, n. 1, 2011, pp.219-233 [https://doi.org/10.17428/rmi.v6i20.1066].

LIDOLA, M. Of Grooming Bodies and Caring Souls: New-Old Forms of Care Work in Brazilian Waxing Studios in Berlin. In: ALBER, E.; DROTBOHM, H. (ed.). Anthropological Perspectives on Care: Work, Kinship, and the Life-Course. New York, Palgrave Macmillan US, 2015, pp.69-90.

LIN, W.; YEOH, B. S. A. Pathological (Im)mobilities: managing risk in a time of pandemics. Mobilities v. 16, n. 1, 2 jan. 2021, pp.96-112 [https://doi.org/10.1080/17450101.2020.1863550].

LUCCHESE, S. P. et al. Finding the Silver Lining: Aging Well Amongst Older Brazilian Women in the PostMigration Context. Canadian Journal of Nursing Research, 22 mar. 2021, p. 08445621211004332 [https://doi.org/10.1177/08445621211004332].

LUGONES, M. Colonialidad y Género. Tabula Rasa v. 9, 2008, pp.73-101 [https://revistas.unicolmayor.edu.co/index.php/tabularasa/article/view/1501 - acesso: 16 ago 2010].

MAHLER, S. J.; PESSAR, P. R. Gendered Geographies of Power: Analyzing Gender Across Transnational Spaces. Identities v. 7, n. 4, 1 jan. 2001, pp.441-459 [https://doi.org/10.1080/1070289X.2001.9962675].

MALHEIROS, J.; PADILLA, B. Can stigma become a resource? The mobilization of aesthetic-corporal capital by female immigrant entrepreneurs from Brazil. Identities: Global Studies in Culture and Power, 2015, pp.687-705 [https://doi.org/10.4324/9781315226491-4].

MCDONNELL, J.; LOURENÇO, C. DE. You're Brazilian, right? What kind of Brazilian are you? The racialization of Brazilian immigrant women. Ethnic and Racial Studies v. 32, n. 2, 1 fev. 2009, pp.239-256 [https://doi.org/10.1080/01419870802361328].

MCILWAINE, C.; EVANS, Y. Urban Violence Against Women and Girls (VAWG) in transnational perspective: reflections from Brazilian women in London. International development planning review v. 42, n. 1, 13 jan. 2020, pp.93-112 [https://doi.org/10.3828/idpr.2018.31].

MESSIAS, D. K. H. Transnational Health Resources, Practices, and Perspectives: Brazilian Immigrant Women's Narratives. Journal of Immigrant Health v. 4, n. 4, 1 out. 2002, pp.183-200 [https://doi.org/10.1023/A:1020154402366].

PADILLA, B.; FRANÇA, T. A imigração brasileira desde uma perspectiva de gênero. In: PEIXOTO, J. et al. (ed.). Vagas Atlânticas - Migrações entre Brasil e Portugal no início do Século XXI. Lisboa, Portugal, Mundos Sociais, 2015, pp.89-108.

PAREDES, J. Hilando Fino (Desde el feminismo comunitario). La Paz, CEDEC, 2008. 
PISCITELLI, A. Looking for New Worlds: Brazilian Women as International Migrants. Signs: Journal of Women in Culture and Society, v. 33, n. 4, 1 jun. 2008a, pp.784-793 [https://doi.org/10.1086/528747].

PISCITELLI, A. Interseccionalidades, categorias de articulação e experiências de migrantes brasileiras. Sociedade e Cultura v. 11, n. 2, 18 dez. 2008b [https://doi.org/10.5216/sec.v11i2.5247].

PISCITELLI, A. Transnational Sex Travels: Negotiating Identities in a Brazilian "Tropical Paradise". In: ALVAREZ, S. et alii (ed). Translocalities/Translocalidades: Feminist Politics of Translation in the Latin/a Américas. New York, USA, Duke University Press, 2014, pp.277-296.

PISCITELLI, A.; ASSIS, G.; OLIVAR, J. Gênero, sexo, amor e dinheiro: mobilidades transnacionais envolvendo o Brasil. Unicamp, Pagu, 2011.

PONTES, L. Mulheres brasileiras na midia portuguesa. cadernos pagu (23), Campinas, SP, Núcleo de Estudos de Gênero-Pagu/Unicamp, 2004, pp.229-256 [https://periodicos.sbu.unicamp.br/ojs/index.php/cadpagu/article/view/8644663 - acesso em: 01 dez 2008].

QUIJANO, A. Colonialidad y Modernidad-racionalidad. In: BONILLO, H. (ed.). Los Conquistados. Bogota, Tecer Mundo Ediciones, 1992, pp.437-449.

WATARAI, T. Can a Mestiça be a Haafu? Japanese-Brazilian Female Migrants and the Celebration of Racial Mixing in Contemporary Japan. Journal of Intercultural Studies v. 35, n. 6, 2 nov. 2014, pp.662-676 [https://doi.org/10.1080/07256868.2014.967188]. 